\title{
ZS Research Suare \\ Choroidal and Retinal Thickness in Patients with Vitamin C Deficiency
}

\section{Yiwen Qian}

Huashan Hospital Fudan University

\section{Luoziyi Wang}

Huashan Hospital Fudan University

\section{Xinfang Qiang}

Huashan Hospital Fudan University

\section{Huan Weng}

Huashan Hospital Fudan University

\section{Jing Jiang}

Huashan Hospital Fudan University

\section{Xin Che}

Huashan Hospital Fudan University

\section{Qingjian Li}

Huashan Hospital Fudan University

Zhiliang Wang ( $\sim$ ophwzl@163.com )

Huashan Hospital Fudan University https://orcid.org/0000-0003-0944-8584

\section{Research}

Keywords: vitamin C, choroidal thickness, retinal thickness, SS-OCT, reactive oxygen species

Posted Date: July 27th, 2021

DOI: https://doi.org/10.21203/rs.3.rs-730565/v1

License: (c) (i) This work is licensed under a Creative Commons Attribution 4.0 International License. Read Full License 


\section{Abstract}

Purpose: to investigate the effects of vitamin C on central retinal thickness and choroidal thickness.

Methods: A total of 72 patients diagnosed with vitamin $C$ deficiency and 1:1 age- and gender-matched 72 healthy individuals with normal serum vitamin $\mathrm{C}$ were included in this study. Demographic characteristics of the individuals were collected. All patients underwent a comprehensive ophthalmic examination. Subfoveal choroidal thickness and retinal thickness were measured using a swept-source optical coherence tomography (SS-OCT).

Results: The average retinal thickness was $268.96 \pm 14.01$ um in the vitamin C deficiency group and $276.69 \pm 13.28$ um in the control group. The average choroidal thickness was $195.06 \pm 66.35$ um in the in the vitamin $C$ deficiency group and $238.53 \pm 56.20$ um in the control group. There was a significant decrease in both average choroidal thickness and retinal thickness in vitamin $C$ deficiency group compared with normal individuals $(p<0.001$, and $=0.003$ respectively).

Conclusion: The central retinal and choroidal thickness were thinner in vitamin C deficiency group compared with normal individuals. These findings suggested that vitamin $\mathrm{C}$ deficiency might play an important role in retinal and choroidal diseases.

\section{Introduction}

The retina, a layer of nervous tissue, is rich in polyunsaturated fatty acids (PUFA) and highly susceptible to lipid peroxidation(1). The prolonged exposure to radiant energy, elevated metabolic activity and oxygen consumption may lead to reactive oxygen species (ROS)-mediated apoptosis in retina cells, especially the photoreceptor cells and retinal pigment epithelium(2). Prior studies have observed oxidative stress is relevant to the pathophysiology of retinal diseases, such as age-related macular degeneration (AMD), diabetic retinopathy and glaucoma(2-4).

The choroid, with the highest blood flow rates in the body, is of vital importance to the etiology and physiology of retina by providing oxygen and nutrients to the outer retinal layers and removing waste products from the eye. Choroid plays a pivotal role in many retinal diseases, such as age-related macular degeneration (AMD), glaucoma, uveitis, diabetic retinopathy, etc. $(5,6)$. Accurate measurement of choroidal thickness is an important step in monitoring disease onset and progression that lead to choroidal thinning.

For the relationship between ROS and various retinal diseases, mechanism of removal of free radicals by antioxidant has been studied in recent years $(7,8)$. Vitamin $C$ is an antioxidant for humans, with pleiotropic functions such as antioxidation and a cofactor of a large number of biosynthetic and gene regulatory enzymes. Supplementation of vitamin $\mathrm{C}$ also contributes to immune defense by improving the function of the human innate and adaptive immune system, such as antimicrobial and natural killer cell activities, lymphocyte proliferation(9). A cumulative number of studies on animal and human with dietary supplementation of antioxidants (including vitamin $\mathrm{C}$ ) were found to restore glutathione level and inhibit oxidative damage in the retina(10).

The retina and choroid both possess a high concentration of vitamin $\mathrm{C}$ transporters (sodium-vitamin $\mathrm{C}$ cotransporter) SVCT2(11). Therefore, it is important to investigate the effect of antioxidant of vitamin $\mathrm{C}$ for the oxidative stress induced damage in retina and choroid. The novel swept-source optical coherence tomography imaging (SS-OCT), with a longer central wavelength $(1050 \mathrm{~nm})$, has the advantage of deeper penetration through the RPE(12). It enables noninvasive visualization and measurement of the choriocapillaris and choroidal vasculature, opening up a new world of research in this previously underexplored ocular tissue. 
To the best of our knowledge, there have been no studies evaluating macular retinal and choroidal thickness with vitamin $\mathrm{C}$ deficiency. The aim of this study is to evaluate the relationship of the vitamin $\mathrm{C}$ level with retinal and choroidal vasculature in normal individuals. Thus, it may help in understanding the etiology of oxidative stress on retina and choroid.

\section{Materials And Methods}

The study included a total of 2185 participants who referred for vitamin analysis performed at Huashan Hospital, Fudan University, Shanghai, China, from May 2019 to December 2019, conforming to the tenets of the Declaration of Helsinki. Approval was obtained from the Institutional Review Board of Huashan Hospital affiliated with Fudan University. All subjects enrolled in the study provided written informed consent before undergoing the examinations. Blood samples of the participants were taken on the same morning for analysis. Vitamin $\mathrm{C}$ deficiency is defined as vitamin $\mathrm{C}$ below standard value $(34 \mu \mathrm{mol} / \mathrm{L}-114 \mu \mathrm{mol} / \mathrm{L})$. The participants were grouped into VC deficiency $(<$ $34 \mu \mathrm{mol} / \mathrm{L}$ ) and normal group ( $\geq 34 \mu \mathrm{mol} / \mathrm{L})$. All participants underwent comprehensive ocular examination including autorefractometer, and slit-lamp biomicroscopy. The study participants had best corrected visual acuities (BCVA) of $20 / 25$ or more, a refractive error in the range +6.0 to -6.0 diopters and intraocular pressure (IOP) between $10 \mathrm{mmHg}$ and $21 \mathrm{mmHg}$. Those with systemic diseases such as hypertension, diabetic mellitus, cardiovascular disease and renal impairment and retinal diseases such as inherited retinal dystrophies, uveitis and AMD or a history of ophthalmic surgery that may have affected the choroidal vascular network were excluded. In addition, poor OCT image due to media opacities or unstable fixation were also excluded. 72 eligible subjects with vitamin $\mathrm{C}$ deficiency were enrolled in and 1:1 age- and sex-paired normal vitamin $C$ subjects were included for control group.

\section{Swept-source optical coherence tomography imaging}

OCT images were obtained with an SS-OCT (DRI OCT-1 Atlantis, Version 9.31, Topcon Co., Tokyo, Japan) which overcomes the scattering of light on the choroid due to longer wavelength of approximate $1050 \mathrm{~nm}$. The macular retinal thickness and choroidal thickness were defined respectively as the distance from the internal limiting membrane (ILM) to the basal edge of the retinal pigment epithelium (RPE) and the distance from the outer border of the RPE to the chorioscleral interface (CSI). Thickness map were created automatically in accordance with the standard Early Treatment Diabetic Retinopathy Study (ETDRS) subfield. For every OCT scans, each segmented layer line can be manually adjusted to avoid automatic measurement errors. Only the right eye of each participant was assessed for statistical analysis. The OCT scanning were performed during the same daily interval (8-10am) to avoid diurnal variations in retinal and choroidal thickness and performed by the same skilled technician who was blinded to the blood results.

\section{Statistical analysis}

SPSS statistical analysis software (SPSS, Version 24.0, IBM Inc., Chicago, IL, USA) was used for all statistical analyses. Values were expressed as mean \pm standard deviation(SD). Continuous data were compared using the Student's t-test. Pearson's correlation coefficient was used to test the relationships between choroidal thickness, choroidal thickness and vitamin C. Statistical significance was defined as 2 -tailed p-value $<0.05$.

\section{Results}

Table 1 listed the baseline characteristics of the participants. 72 patients with vitamin $\mathrm{C}$ deficiency and 72 healthy controls were matched by sex and age (1:1 pair-wise matching). The mean vitamin C level was 31.30 $\mu \mathrm{mol} / \mathrm{L}$ in vitamin $\mathrm{C}$ deficiency group and $39.49 \mu \mathrm{mol} / \mathrm{L}$ in control group. The average age of the vitamin $\mathrm{C}$ deficiency group was $57.07 \pm$ 
15.13 years old in vitamin deficiency group and $57.97 \pm 12.96$ years old in control group. There was also no significant difference in blood pressure between the vitamin $\mathrm{C}$ deficiency group and control group.

\section{Table 1}

Demographic characteristics

\begin{tabular}{llll} 
Parameter & Vitamin C deficiency group & Control group & P Value \\
\hline Patient, $\mathrm{n}$ & 72 & 72 & - \\
\hline Eye, $\mathrm{n}$ & 72 & 72 & - \\
\hline Gender, $\mathrm{n}$ & & & \\
\hline Male & 39 & 39 & \\
\hline Female & 33 & 33 & $0.700^{\mathrm{a}}$ \\
\hline Age, year & $57.07 \pm 15.13$ & $57.97 \pm 12.96$ & \\
\hline Range & $30-80$ & $30-80$ & $0.206^{\mathrm{a}}$ \\
\hline SBP, $\mathrm{mmHg}$ & 127.07 & 124.18 & $0.365^{\mathrm{a}}$
\end{tabular}

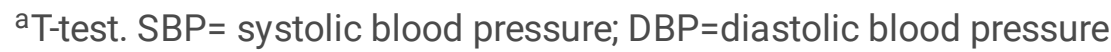

Data showed the average retinal thickness was significantly decreased in the vitamin $\mathrm{C}$ deficiency group compared with the control group $(268.96 \pm 14.01$ vs $276.69 \pm 13.28, p=0.001)$. What's more, the retinal thickness in the vitamin $C$ deficiency group was thinner at all nine sectors of retina compared with the control group, among which the center and the inner sectors of the retina have the most significant decrease of retinal thickness. (Table 2 and Figure 1).

Table 2

Retinal thickness of nine sectors of the ETDRS grid. 


\begin{tabular}{llll} 
Retinal thickness & Vitamin C deficiency group & control group & P Value \\
& $\mathrm{n}=72$ & $\mathrm{n}=72$ & \\
\hline Center, $\mu \mathrm{m}$ & $221.81 \pm 20.99$ & $232.28 \pm 21.96$ & $0.004^{\mathrm{a}}$ \\
\hline Inner superior, $\mu \mathrm{m}$ & $300.19 \pm 17.43$ & $305.97 \pm 16.23$ & $0.041^{\mathrm{a}}$ \\
\hline Inner nasal, $\mu \mathrm{m}$ & $296.42 \pm 19.88$ & $303.76 \pm 17.46$ & $0.020^{\mathrm{a}}$ \\
\hline Inner inferior, $\mu \mathrm{m}$ & $293.82 \pm 19.856$ & $303.36 \pm 19.35$ & $0.004^{\mathrm{a}}$ \\
\hline Inner temporal, $\mu \mathrm{m}$ & $287.52 \pm 16.49$ & $296.42 \pm 18.08$ & $0.002^{\mathrm{a}}$ \\
\hline Outer superior, $\mu \mathrm{m}$ & $270.67 \pm 15.08$ & $275.60 \pm 15.18$ & $0.053^{\mathrm{a}}$ \\
\hline Outer nasal, $\mu \mathrm{m}$ & $281.17 \pm 16.07$ & $290.77 \pm 16.41$ & $0.001^{\mathrm{a}}$ \\
\hline Outer inferior, $\mu \mathrm{m}$ & $253.45 \pm 17.04$ & $259.63 \pm 15.99$ & $0.026^{\mathrm{a}}$ \\
\hline Outer temporal, $\mu \mathrm{m}$ & $250.69 \pm 14.98$ & $256.83 \pm 15.41$ & $0.017^{\mathrm{a}}$ \\
\hline Average thickness, $\mu \mathrm{m}$ & $268.96 \pm 14.01$ & $276.69 \pm 13.28$ & $0.001^{\mathrm{a}}$ \\
\hline
\end{tabular}

a-test.

Data showed that average choroidal thickness was significantly thinner in the vitamin $C$ deficiency group than in the control group (195.06 \pm 66.35 vs $238.53 \pm 56.20$, p < 0.001). In addition, the choroidal thickness of all nine ETDRS sectors showed a significant decrease in the vitamin $\mathrm{C}$ group compared with the control group. (Table 3 and Figure 2).

Table 3

Choroidal thickness of nine sectors of the ETDRS grid. 


\begin{tabular}{llll} 
Choroidal thickness & Vitamin deficiency group & control & P Value \\
& $\mathrm{n}=72$ & group & \\
& & $\mathrm{n}=72$ & \\
\hline Center, $\mu \mathrm{m}$ & $210.75 \pm 71.41$ & $259.78 \pm 59.08$ & $<0.001^{\mathrm{a}}$ \\
\hline Inner superior, $\mu \mathrm{m}$ & $213.61 \pm 75.05$ & $266.52 \pm 64.68$ & $<0.001^{\mathrm{a}}$ \\
\hline Inner nasal, $\mu \mathrm{m}$ & $195.44 \pm 72.51$ & $251.25 \pm 62.90$ & $<0.001^{\mathrm{a}}$ \\
\hline Inner inferior, $\mu \mathrm{m}$ & $208.43 \pm 77.96$ & $254.77 \pm 65.74$ & $<0.001^{\mathrm{a}}$ \\
\hline Inner temporal, $\mu \mathrm{m}$ & $207.80 \pm 70.52$ & $249.58 \pm 57.29$ & $<0.001^{\mathrm{a}}$ \\
\hline Outer superior, $\mu \mathrm{m}$ & $205.64 \pm 70.96$ & $251.58 \pm 63.80$ & $<0.001^{\mathrm{a}}$ \\
\hline Outer nasal, $\mu \mathrm{m}$ & $162.94 \pm 70.30$ & $211.58 \pm 69.61$ & $<0.001^{\mathrm{a}}$ \\
\hline Outer inferior, $\mu \mathrm{m}$ & $198.73 \pm 71.78$ & $236.46 \pm 63.48$ & $0.001^{\mathrm{a}}$ \\
\hline Outer temporal, $\mu \mathrm{m}$ & $197.45 \pm 69.54$ & $231.51 \pm 55.98$ & $<0.001^{\mathrm{a}}$ \\
\hline Average thickness, $\mu \mathrm{m}$ & $195.06 \pm 66.35$ & $238.53 \pm 56.20$ & $<0.001^{\mathrm{a}}$ \\
\hline a T-test. & & & \\
\hline
\end{tabular}

The correlations of retinal thicknesses and Choroidal thicknesses with blood vitamin C level are shown in table 4 and table 5 separately. Both average retinal thicknesses and choroidal thicknesses were associated with Vitamin $\mathrm{C}$ in the entire population ( $r=0.248, p=0.003$ for retinal thickness and $r=0.296, p<0.001$ for choroidal thickness).

Table 4

Correlation analysis results between retinal thickness and Vitamin C

\begin{tabular}{|c|c|c|c|c|c|c|c|c|c|c|c|}
\hline \multicolumn{2}{|c|}{$\begin{array}{l}\text { Retinal } \\
\text { thickness }\end{array}$} & Center & I-S & $\mathrm{I}-\mathrm{N}$ & $\mathrm{I}-\mathrm{I}$ & $\mathrm{I}-\mathrm{T}$ & O-S & $\mathrm{O}-\mathrm{N}$ & $0-1$ & O-T & Average \\
\hline \multirow[b]{2}{*}{ VC } & $r$ & $0.251^{\star *}$ & $0.228^{\star \star}$ & $0.223^{\star \star}$ & $0.294^{\star \star}$ & $0.261^{\star \star}$ & 0.136 & $0.198^{*}$ & $0.167^{*}$ & $0.179^{*}$ & $0.248^{\star \star}$ \\
\hline & $\mathrm{p}$ & 0.002 & 0.006 & 0.007 & $<0.001$ & 0.002 & 0.103 & 0.017 & 0.046 & 0.031 & 0.003 \\
\hline \multicolumn{12}{|c|}{${ }^{*} p<0.05,{ }^{* *} p<0.01$} \\
\hline
\end{tabular}

Table 5

Correlation analysis results between choroidal thickness and Vitamin C 


\begin{tabular}{|c|c|c|c|c|c|c|c|c|c|c|c|}
\hline \multicolumn{2}{|c|}{$\begin{array}{l}\text { Choroidal } \\
\text { thickness }\end{array}$} & Center & I-S & $\mathrm{I}-\mathrm{N}$ & $\mathrm{H}$ & I-T & O-S & $\mathrm{O}-\mathrm{N}$ & $0-1$ & O-T & Average \\
\hline \multirow[b]{2}{*}{ V C } & $r$ & $0.298^{\star \star}$ & $0.303^{\star \star}$ & $0.305^{\star \star}$ & $0.268^{\star \star}$ & $0.295^{\star \star}$ & $0.269^{\star \star}$ & $0.291^{\star \star}$ & $0.231^{*}$ & $0.268^{\star \star}$ & $0.295^{\star \star}$ \\
\hline & $\mathrm{p}$ & $<0.001$ & $<0.001$ & $<0.001$ & 0.001 & $<0.001$ & 0.001 & $<0.001$ & 0.06 & 0.001 & $<0.001$ \\
\hline \multicolumn{12}{|c|}{${ }^{*} p<0.05,{ }^{* *} p<0.01$} \\
\hline \multicolumn{12}{|c|}{$\begin{array}{l}\text { I-S, innr superior; I-N, inner nasal; I-I, inner inferior; I-T, inner temporal; O-S, outer superior; O-N, outer nasal; O-I, outer } \\
\text { inferior; O-T, outer temporal; VC, vitamin C }\end{array}$} \\
\hline
\end{tabular}

\section{Discussion}

Oxidative stress due to vitamin $\mathrm{C}$ deficiency has been implicated as critical pathogenic factors contributing to the etiology of retinal and choroidal diseases(10). A cumulative research has focused on the protection of retinal and choroidal physiology and function by vitamin $\mathrm{C}$ supplementation due to its antioxidative properties. In our current study, we found that both the retinal and choroidal thickness significantly decreased in the vitamin $\mathrm{C}$ deficiency group compared with age- and gender- matched normal vitamin $\mathrm{C}$ individuals. This result might suggest a close correlation between vitamin $\mathrm{C}$ deficiency with the retinal and choroidal diseases.

An imbalance between ROS and antioxidants in the body may result in excessive generation of ROS, including hydrogen peroxide, superoxide and peroxynitrate. These insults may damage cellular macromolecules and organelles and promote cell death via apoptosis. Vitamin $\mathrm{C}$ is an important antioxidant which can prevent the oxidative damage to the retina(13). A high level of vitamin $C$ in retina alleviates free radicals and improves immune cell function generated by its high metabolic activity(9). As a result, there has been persistent interest in antioxidant approaches (such as vitamin $\mathrm{C}$ ) to combat oxidative stress in retinal diseases.

The retina and choroid possess a high-affinity transport system for vitamin $\mathrm{C}$ and the highest concentration of vitamins was located in the RPE followed by the outer segments of the photoreceptor cells(14). Both in vivo and in vitro experiments have verified the prominent effect of vitamin $C$ in retina health(14). In animal model of vitamin $C$ deficiency, short-term low vitamin C level would induce oxidative stress in the retinas of young guinea pigs $(15,16)$. In a model of porcine hypercholesterolemia, vitamins $\mathrm{C}$ improved retinal structure alteration in transmission electron microscopy by preventing oxidative stress and nitric oxide metabolites(17). In an oxidative stress model induced by hydrogen peroxide and ultraviolet B irradiation of ARPE-19 cells, antioxidative effect of vitamin C could result in increment in cell viability and reduction in intracellular ROS level(18). The study of AREDS showed that treatment of high dose antioxidant supplements in patients with intermediate AMD was effective in retarding the progression of AMD compared with placebo $(19,20)$.

Mechanisms by which vitamin C deficiency correlated with retinal and choroidal thickness are multifactorial. Vitamin $\mathrm{C}$ deficiency may increase oxidative stress which directly contributes to apoptosis, damaging of retina cells (especially the photoreceptor cell) and activation of retinal immune system. The decrease of retinal thickness may due to the thinning of the photoreceptor cell layer caused by apoptosis, shortening of the photoreceptor cell outer segment. In an animal study, spaceflight inducing oxidative damage resulted an increase in photoreceptor cone damage, and reduction of thickness of the retinal outer nuclear layer (ONL), retinal inner nuclear layer (INL), RPE, and choroid layers of the eye in C57BL/6 mice(21). In retinal glial cells, oxidative stress increased the expression of major 
histocompatibility complex (MHC) II, consequently improving the ability to stimulate T cell proliferation and secretion of cytokines (TNFa) that can induce glial cell apoptosis(22). As the cones contain more mitochondria and have a higher energy demand than rods, it is much more prone to be affected by oxidative stress(23). In our study, the center and the inner sectors of the retina showed the most significant difference between the two groups, while the outer sectors had a trend of retinal thinning without significant difference.

The second possibility was role of vitamin $\mathrm{C}$ in the function of vascular endothelium(24). Ascorbate has long been known to enhance endothelial synthesis and deposition of Type IV collagen to form the basement membrane of blood vessels. Cell experiment demonstrated that vitamin $C$ could tighten the endothelial permeability barrier and control endothelial cell proliferation and apoptosis resulting from many dioxygenase involved in endothelial function, proliferation, and survival(24). Recent studies have found that low vitamin C concentration is linked with vascular disease, such as atherosclerosis and cardiovascular diseases due to endothelial dysfunction $(25,26)$. High dose of vitamin $\mathrm{C}$ administration showed beneficial function in endothelial function in various artery diseases $(27,28)$.

Moreover, vitamin $\mathrm{C}$ is closely associated with inflammatory regulation. A cumulative researches have confirmed that inflammation is a critical factor contributing to the pathogenesis of many microvascular disorders $(29,30)$. Retinal and choroidal thickness showed close relation with inflammatory diseases (31). Balmforth et al. revealed a choroidal thinning with increased IL-6, TNF-a and endothelin-1 due to inflammation and endothelial dysfunction(32). These might be the reasons contributing to the significant difference in retinal and choroidal thickness between the two groups.

Although the retina is extremely sensitive to oxidative stress, retinal thickness in the vitamin C deficiency does not have such a remarkable thinning as the choroidal thickness. The possible explanation is the high blood flow of choroidal vasculature compared with retina vessels. Moreover, regulation of blood flow to the retina and the choroid is quite different: retinal flow vasculature can accommodate autogenously, while choroidal flow relies on autonomic regulation.

The present study has several limitations. First, although we have included 100 individuals, we still need a larger population to evaluate the effect of vitamin $\mathrm{C}$ in choroidal and retinal vasculature. Secondly, we did not assess the smoking population among the subjects while cigarette was believed to be partially responsible for choroid thinning. Future prospective studies of serum antioxidants and incident of retina and choroid thinning may help to further clarify the effect of antioxidants on the health of retina and choroid.

\section{Conclusions}

In conclusion, there is a strong relationship of vitamin C deficiency with choroidal and retinal thinning, for the unique antioxidant/protective activities in the retina. Given that patients with vitamin C deficiency might lead to the development choroidal and retinal vasculature problems, it might help new strategies for prevention of treatment for oxidative stress in retinopathy.

\section{Abbreviations}

SS-OCT: swept-source optical coherence tomography

PUFA : polyunsaturated fatty acids

ROS : reactive oxygen species 
AMD : age-related macular degeneration

SVCT2 : sodium-vitamin C cotransporter

IOP : intraocular pressure

ILM : internal limiting membrane

RPE : retinal pigment epithelium

CSI : chorioscleral interface

ETDRS : Early Treatment Diabetic Retinopathy Study

MHC : major histocompatibility complex

ONL : outer nuclear layer

INL : retinal inner nuclear layer

\section{Declarations}

\section{Acknowledgements}

Not applicable.

\section{Funding}

This work was supported by grants from the Natural Science Foundation of China (No. 81670868 and No. 81900879).

\section{Availability of data and materials}

The datasets used and analyzed during the current study are available from the corresponding author upon reasonable request.

\section{Authors' contributions}

Research design was conducted by ZW, YQ and LW. Data collection was undertaken by HW, YQ and QL. Data analysis and interpretation were performed by XC, XQ and JJ. The manuscript was finished by YQ, LW, XQ, XC, HW, JJ, QL and $W Z$, and revised by ZW and $Y Q$.

\section{Ethics approval and consent to participate}

The research was approved by the Institutional Review Board of Huashan Hospital affiliated to Fudan University and performed following the tenets of the Declaration of Helsinki. The subjects in the study signed written informed consent before undergoing the examination. 


\section{Consent for publication}

All of the authors gave their consent to the publication. No conflict of interest exits in the submission of this manuscript, and this manuscript is approved by all of the authors for publication. The work described was original research that has not been published previously, and is not under consideration for publication elsewhere, in whole or in part.

\section{Competing interests}

The authors declare that they have no competing interests.

\section{References}

1. Yu DY, Cringle SJ. Retinal degeneration and local oxygen metabolism. Exp Eye Res. 2005;80:745-51.

2. Jarrett SG, Boulton ME. Consequences of oxidative stress in age-related macular degeneration. Mol Aspects Med. 2012;33:399-417.

3. Lawler T, Liu Y, Christensen K, Vajaranant TS, Mares J. Dietary Antioxidants, Macular Pigment, and Glaucomatous Neurodegeneration: A Review of the Evidence. Nutrients.(2019) 11.

4. Mao H, Seo SJ, Biswal MR, Li H, Conners M, Nandyala A, Jones K, Le YZ, Lewin AS. Mitochondrial oxidative stress in the retinal pigment epithelium leads to localized retinal degeneration. Invest Ophthalmol Vis Sci. 2014;55:461327.

5. Nickla DL, Wallman J. The multifunctional choroid. Progress in retinal eye research. 2010;29:144-68.

6. Cicinelli MV, Rabiolo A, Sacconi R, Lamanna F, Querques L, Bandello F, Querques G. Retinal vascular alterations in reticular pseudodrusen with and without outer retinal atrophy assessed by optical coherence tomography angiography. The British journal of ophthalmology. 2018;102:1192-8.

7. Sin HP, Liu DT, Lam DS. Lifestyle modification, nutritional and vitamins supplements for age-related macular degeneration. Acta ophthalmologica. 2013;91:6-11.

8. Evans JR, Lawrenson JG. Antioxidant vitamin and mineral supplements for slowing the progression of age-related macular degeneration. Cochrane Database Syst Rev. 2017;7:CD000254.

9. De la Fuente M, Sanchez C, Vallejo C, Diaz-Del Cerro E, Arnalich F, Hernanz A. Vitamin C and vitamin C plus E improve the immune function in the elderly. Exp Gerontol. 2020;142:111118.

10. Sadaba LM, Fernandez-Robredo P, Rodriguez JA, Garcia-Layana A. Antioxidant effects of vitamins $C$ and E, multivitamin-mineral complex and flavonoids in a model of retinal oxidative stress: the ApoE-deficient mouse. Exp Eye Res. 2008;86:470-9.

11. Ulloa V, Garcia-Robles M, Martinez F, Salazar K, Reinicke K, Perez F, Godoy DF, Godoy AS, Nualart F. Human choroid plexus papilloma cells efficiently transport glucose and vitamin C. J Neurochem. 2013;127:403-14.

12. Vira J, Marchese A, Singh RB, Agarwal A. Swept-source optical coherence tomography imaging of the retinochoroid and beyond. Expert Rev Med Devices. 2020;17:413-26.

13. De la Fuente M, Cruces J, Hernandez O, Ortega E. Strategies to improve the functions and redox state of the immune system in aged subjects. Curr Pharm Des. 2011;17:3966-93.

14. Domith I, Socodato R, Portugal CC, Munis AF, Duarte-Silva AT, Paes-de-Carvalho R. Vitamin C modulates glutamate transport and NMDA receptor function in the retina. J Neurochem. 2018;144:408-20. 
15. Ohta Y, Okubo T, Niwa T, Yamasaki T, Horiguchi M. Prolonged marginal ascorbic acid deficiency induces oxidative stress in retina of guinea pigs. Int J Vitam Nutr Res. 2002;72:63-70.

16. Ohta Y, Okubo T, Niwa T, Yamasaki T, Horiguchi M. Short-term ascorbic acid deficiency induced oxidative stress in the retinas of young Guinea pigs. J Biomed Sci. 2004;11:172-8.

17. Fernandez-Robredo P, Moya D, Rodriguez JA, Garcia-Layana A. Vitamins $C$ and e reduce retinal oxidative stress and nitric oxide metabolites and prevent ultrastructural alterations in porcine hypercholesterolemia. Invest Ophthalmol Vis Sci. 2005;46:1140-6.

18. Oh S, Kim YJ, Lee EK, Park SW, Yu HG. Antioxidative Effects of Ascorbic Acid and Astaxanthin on ARPE-19 Cells in an Oxidative Stress Model. Antioxidants (Basel).(2020) 9.

19. Age-Related Eye Disease Study Research G. A randomized, placebo-controlled, clinical trial of high-dose supplementation with vitamins $\mathrm{C}$ and $\mathrm{E}$, beta carotene, and zinc for age-related macular degeneration and vision loss: AREDS report no. 8. Arch Ophthalmol. 2001;119:1417-36.

20. Chew EY, Clemons TE, Agron E, Sperduto RD, Sangiovanni JP, Kurinij N, Davis MD. Age-Related Eye Disease Study Research $\mathrm{G}$. Long-term effects of vitamins $\mathrm{C}$ and $\mathrm{E}$, beta-carotene, and zinc on age-related macular degeneration: AREDS report no. 35. Ophthalmology. 2013;120:1604-11 e1604.

21. Overbey EG, da Silveira WA, Stanbouly S, Nishiyama NC, Roque-Torres GD, Pecaut MJ, Zawieja DC, Wang C, Willey JS, Delp MD, et al. Spaceflight influences gene expression, photoreceptor integrity, and oxidative stress-related damage in the murine retina. Sci Rep. 2019;9:13304.

22. Tezel G, Yang X, Luo C, Peng Y, Sun SL, Sun D. Mechanisms of immune system activation in glaucoma: oxidative stress-stimulated antigen presentation by the retina and optic nerve head glia. Invest Ophthalmol Vis Sci. 2007;48:705-14.

23. Primiano G, Abed E, Corbo G, Minnella AM, Servidei S, Vollono C, Savastano MC, Falsini B. Macular impairment in mitochondrial diseases: a potential biomarker of disease severity. Sci Rep. 2020;10:8554.

24. May JM, Harrison FE. Role of vitamin C in the function of the vascular endothelium. Antioxid Redox Signal. 2013;19:2068-83.

25. Langlois M, Duprez D, Delanghe J, De Buyzere M, Clement DL. Serum vitamin C concentration is low in peripheral arterial disease and is associated with inflammation and severity of atherosclerosis. Circulation. 2001;103:18638.

26. Price KD, Price CS, Reynolds RD. Hyperglycemia-induced ascorbic acid deficiency promotes endothelial dysfunction and the development of atherosclerosis. Atherosclerosis(. 2001;158:1-12.

27. Ashor AW, Lara J, Mathers JC, Siervo M. Effect of vitamin C on endothelial function in health and disease: a systematic review and meta-analysis of randomised controlled trials. Atherosclerosis. 2014;235:9-20.

28. Zhu YB, Zhang YP, Zhang J, Zhang YB. Evaluation of Vitamin C Supplementation on Kidney Function and Vascular Reactivity Following Renal Ischemic Injury in Mice. Kidney Blood Press Res. 2016;41:460-70.

29. Giacobbe DT, Murray MJ. Vascular disease and inflammation. Anesthesiol Clin North Am.(2004) 22:183-197, v.

30. Lenart N, Brough D, Denes A. Inflammasomes link vascular disease with neuroinflammation and brain disorders. Journal of cerebral blood flow metabolism: official journal of the International Society of Cerebral Blood Flow Metabolism. 2016;36:1668-85.

31. Steiner M, Esteban-Ortega MDM, Munoz-Fernandez S. Choroidal and retinal thickness in systemic autoimmune and inflammatory diseases: A review. Survey of ophthalmology. 2019;64:757-69.

32. Balmforth C, van Bragt JJ, Ruijs T, Cameron JR, Kimmitt R, Moorhouse R, Czopek A, Hu MK, Gallacher PJ, Dear JW, et al. Chorioretinal thinning in chronic kidney disease links to inflammation and endothelial dysfunction. $\mathrm{JCl}$ 
Figures

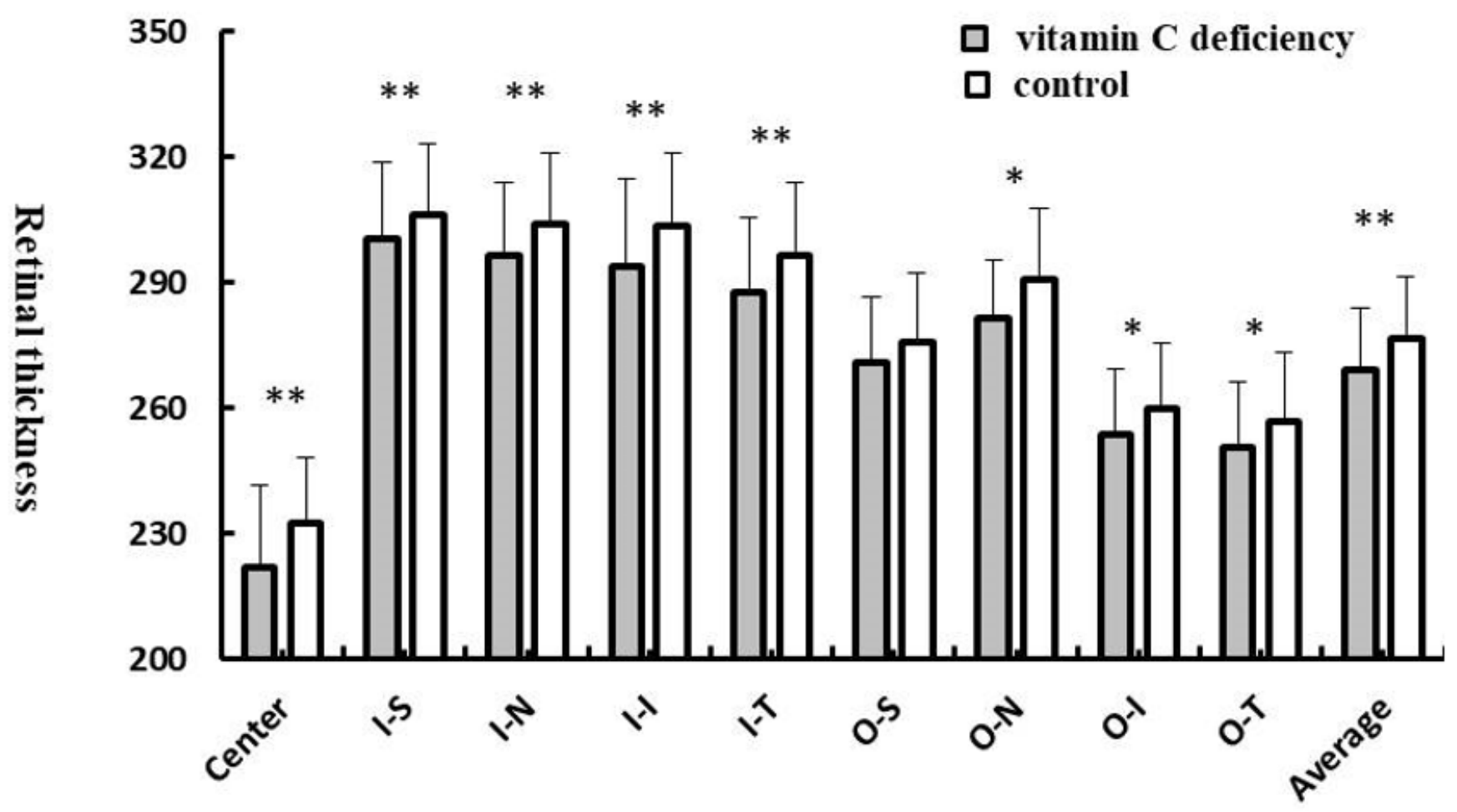

Figure 1

The retinal thickness of nine sectors of the ETDRS grid in the vitamin $\mathrm{C}$ deficiency group compared with the controls. I$\mathrm{S}$, innr superior; I-N, inner nasal; I-I, inner inferior; I-T, inner temporal; O-S, outer superior; O-N, outer nasal; O-I, outer inferior; O-T, outer temporal * $\mathrm{p}<0.05$, ** $\mathrm{p}<0.01$ 


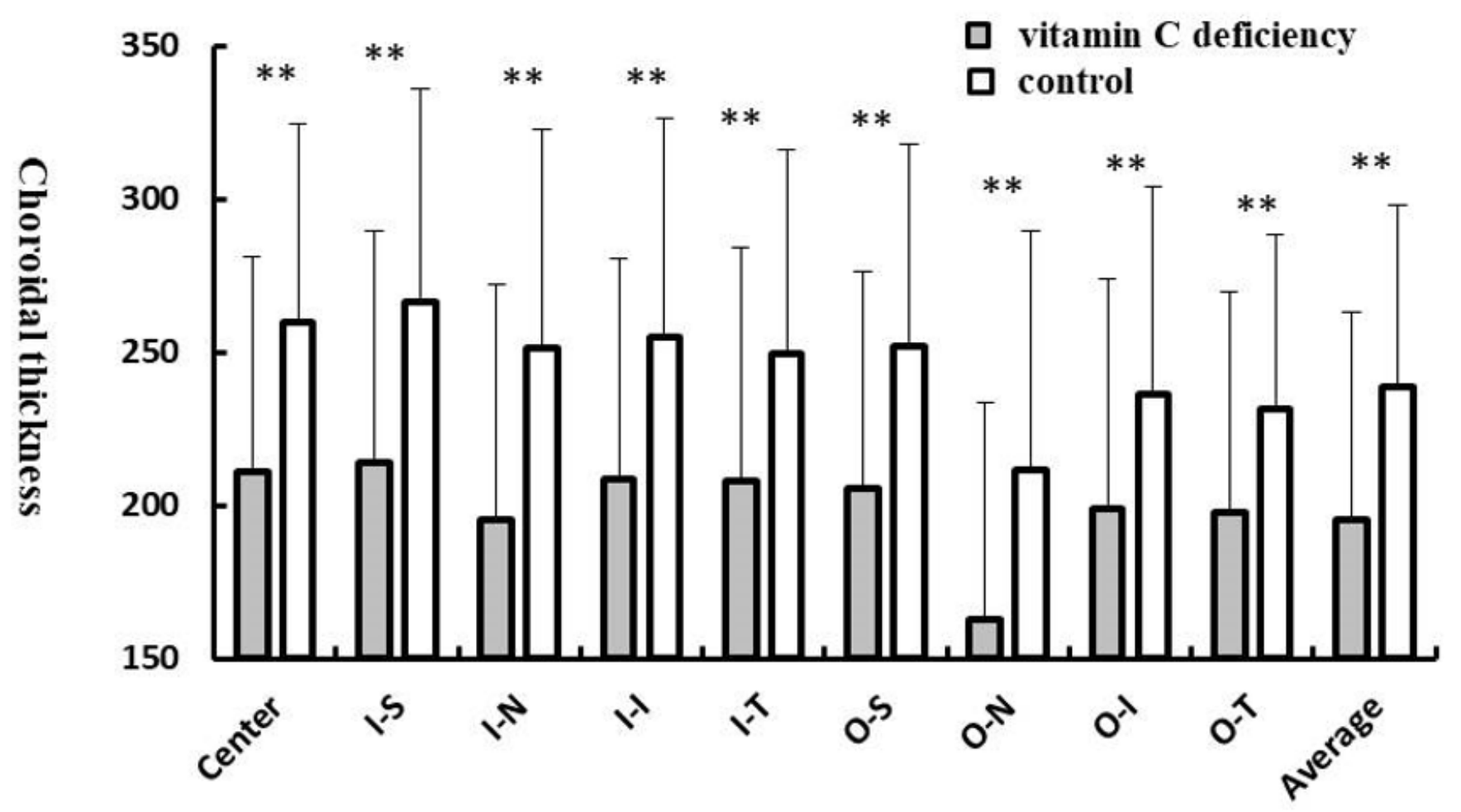

Figure 2

The choroidal thickness of nine sectors of the ETDRS grid in the vitamin C deficiency group compared with the controls. * $\mathrm{p}<0.05$, ** $\mathrm{p}<0.01 \mathrm{I}-\mathrm{S}$, innr superior; I-N, inner nasal; I-I, inner inferior; I-T, inner temporal; O-S, outer superior; O-N, outer nasal; O-I, outer inferior; O-T, outer temporal 